\section{Correction: Trend of lipid and thyroid function tests in adults without overt thyroid diseases: A cohort from Tehran thyroid study}

\section{Salma Ahi, Atieh Amouzegar, Safoora Gharibzadeh, Hossein Delshad, Maryam Tohidi, Fereidoun Azizi}

There is an error in affiliation 3 for author Maryam Tohidi. The correct affiliation 3 is: Prevention of Metabolic Disorders Research Center, Research Institute for Endocrine Sciences, Shahid Beheshti University of Medical Sciences, Tehran, Iran.

\section{Reference}

1. Ahi S, Amouzegar A, Gharibzadeh S, Delshad H, Tohidi M, Azizi F (2019) Trend of lipid and thyroid function tests in adults without overt thyroid diseases: A cohort from Tehran thyroid study. PLoS ONE 14(5): e0216389. https://doi.org/10.1371/journal.pone.0216389 PMID: 31095584
G open ACcess

Citation: Ahi S, Amouzegar A, Gharibzadeh S, Delshad H, Tohidi M, Azizi F (2019) Correction: Trend of lipid and thyroid function tests in adults without overt thyroid diseases: A cohort from Tehran thyroid study. PLOS ONE 14(7): e0220324. https://doi.org/10.1371/journal.pone.0220324

Published: July 23, 2019

Copyright: ๑ 2019 Ahi et al. This is an open access article distributed under the terms of the Creative Commons Attribution License, which permits unrestricted use, distribution, and reproduction in any medium, provided the original author and source are credited. 